\title{
Discover the True Science of Multispecialty Light-Emitting Diode Low Level Light Therapy (LED-LLLT)
}

\author{
R Glen Calderhead, MSc, PhD, \\ DrMedSci FRSM
}

Principal, L'ACADÉMIE Clinical Research \& Training, Goyang, Korea

Received March 14, 2020

Revised April 3, 2020

Accepted April 11, 2020

\section{Correspondence}

R Glen Calderhead

Principal, L'ACADÉMIE Clinical Research \&

Training, Goyang 10534, Korea

E-mail: docrgc1213@gmail.com

https://orcid.org/0000-0002-6911-5151

(c) Korean Society for Laser, Dermatology and Trichology

(c) This is an open access article distributed under the terms of the Creative Commons Attribution NonCommercial License (http://creativecommons.org/ licenses/by-nc/4.0) which permits unrestricted noncommercial use, distribution, and reproduction in any medium, provided the original work is properly cited.

\section{Background and Objectives}

Low level light therapy (LLLT) is the therapeutic indication of light energy to achieve a clinical effect in an athermal and atraumatic way, and includes applications in wound healing and pain attenuation. Light emitting diodes (LEDs) have become the light source of choice with quasimonochromaticity giving laser-like target specificity, so LED-LLLT is amassing a growing body of solid evidence in the international literature.

\section{Photobiological basics of LLLT}

LLLT involves a direct energy transfer between incident photons and their target cells, boosting thecellular energy pool without causing heat or damage. If such photoactivated cells are compromised, they will be repaired. If they are functional cells, they will perform more efficiently If there are not enough cells, proliferation will occur. In LLLT, wavelength is of prime importance to ensure absorption in the targets, and also determines the intrinsic depth of penetration of the light energy into the target tissue: the light energy must also have sufficient intensity.

The ideal LED-LLLT system

The ideal LED-LLLT system should offer three wavelengths.. $415 \mathrm{~nm}$ in the visible blue is useful to control inflammatory acne. $633 \mathrm{~nm}$ visible red is particularly useful in photodynamic therapy (PDT) and some aspects of hair regrowth. $830 \mathrm{~nm}$ in the near infrared has a wide range of proven targets including, but not limited to, the following: all aspects of wound healing, acute or chronic, traumatic or iatrogenic; attenuation of pain of all entities, acute or chronic; bone repair; nerve repair; sports medicine; and hair regrowth. The HEALITE system (Lutronic Corporation, Goyang, South Korea) meets these criteria and has amassed a good number of panspeciality articles in the peer-reviewed literature. HEALITE embodies the true science of LEDLLLT.

Key words

Light-emitting diode, Photobiomodulation, LLLT, Wound healing, Pain

Supplementary video fille: This article contains supplementary material (It is available at https://youtu.be/RuXDd3uk-I0). 


\section{INTRODUCTION}

The first question must be; "What is light therapy?" Although regarded as a modern technology, the medical application of light, broadly classed as phototherapy, has actually been around for more than 4000 years. Around 2000 BC, in the time of the Pharaoh Amenhotep IV, the Ancient Egyptians were using sunlight with a photosensitizing herb, similar to parsley, to treat systemic vitiligo [1]. They would crush the herb and rub the vitiliginous area with the crushed leaves, then expose the area to the desert sun. Within $24 \mathrm{hr}$ they would have a photomediated horrendous post-inflammatory hyperpigmentation (sunburn), which was followed by postinflammatory hyperpigmentation as the quiescent melanocytes in the depigmented patch were forced into hypermelanosis to protect the skin from further sun damage, thereby repigmenting the depigmented patch. This was termed heliotherapy, (Helios was the Ancient Greek Sun God), and after the Ancient Egyptians this form of treatment was in turn practised by the Ancient Greeks and Romans, before falling into disuse through lack of knowledge in the Dark Ages.

A resurgence of interest was seen in the $19^{\text {th }}$ Century in Great Britain as red light therapy for 'melancholia', which involved shutting the patient in a room with red curtains over the windows. Additionally, patients suffering from tuberculosis of the lungs caused by bad air, and the bone disease rickets (caused by lack of vitamin D due to poor quality sunlight), were sent to 'sanitoria', special hospitals for natural light therapy built on high ground and mountains in the clear air where the sunlight was not filtered by the fumes and smoke of the industrial revolution. However, the sun is a fickle fellow, especially in Northern Europe, and so medicine was happy to welcome the first man-made therapeutic light source controlled at the turn of a switch when the Danish researcher and clinician Niels Finsen introduced his electricity-powered phototherapy system at the turn of the $20^{\text {th }}$ Century for tuberculosis of the skin and lupus vulgaris [2], for which he won the Nobel Prize in 1904. Finally, getting nearer to modern times in the mid 1950s in the UK, neonatal jaundice was found to be cured by exposure to blue light [3].

Perhaps the biggest milestone in phototherapy was the successful development of the first laser in 1960 by Theodore Maiman [4], which gave a new light-based surgical and therapeutic tool to clinicians. Early adopters found that procedures performed with the new "light scalpel" healed well with less inflammation and less pain than similar procedures with the cold steel, and this beneficial effect was isolated as being due to low levels of athermal light energy at the periphery of the laser beam in tissue by the Godfather of phototherapy, Mester [5], in the late 1960s. During the late 1970s and through the 1980s, athermal and atraumatic phototherapy using low incident levels of laser energy garnered attention in wound healing and pain attenuation, with the terminology "Low Level Laser Therapy" being coined by Ohshiro and Calderhead in 1988 [6], with the acronym LLLT. Lasers remained at the heart of LLLT until the late 1990s when Whelan et al. [7], working in the NASA Space Medicine Laboratory, developed the NASA lightemitting diode (LED). This LED was 5 orders of magnitude more powerful than the then-current LEDs, and very narrowband, quasimonochromatic, with more than $98 \%$ of the photons at the rated wavelength offering laser-like target selectivity. Finally another light source, easier to manage and less-expensive than the laser diode, became available to researchers and clinicians, and Low Level Laser Therapy became Low Level LIGHT Therapy [8], but still LLLT, proving very effective in wound healing [9]. Low level light therapy with LEDs (LED-LLLT) had finally arrived as a valid medical tool.

LEDs share the same first letter ' $L$ ' with laser, namely 'light', and so they must follow the rules of photobiology and photochemistry. The first law (the Grotthus-Draper Law) is very clear: if no absorption of the light energy occurs, no reaction will ever take place. The most important determinant of both selection of target, or chromophore, and intrinsic depth of penetration of light, is wavelength, although intensity is also necessary to make sure enough light at the right wavelength reaches deeper targets. Fig. 1 shows the photospectrogram of 'white light' through a human hand in vivo. The photospectrometer delivers the light evenly over the spectrum from $400 \mathrm{~nm}$ to $1100 \mathrm{~nm}$ (visible to near-infrared), and compares the light penetrat-

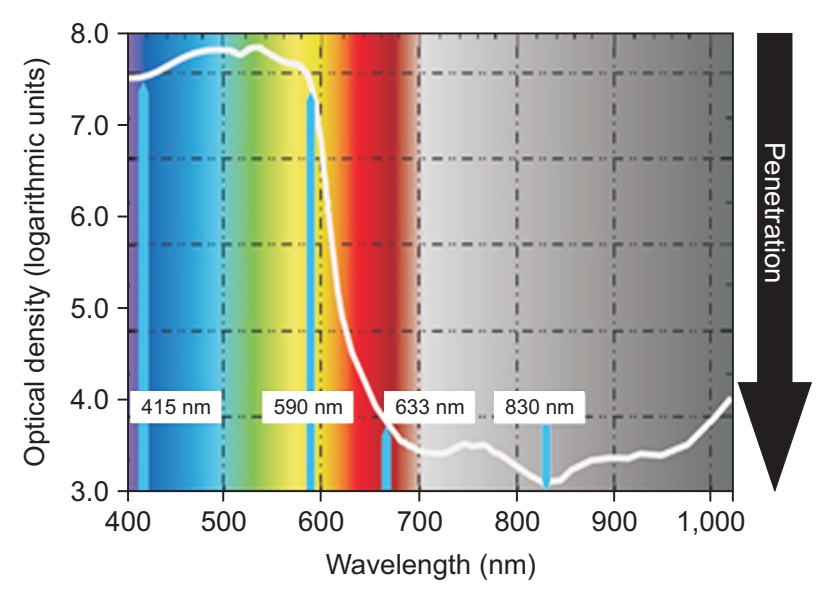

Fig. 1. Photospectrogram of white light through a human hand in vivo. 
ing through the hand with a reference beam to determine the optical density for each wavelength. The OD data are then displayed as a curve plotted on the spectrogram. OD units are logarithmic, so an OD of 3 will allow 100,000 times more light through than an OD of 8 , thereby measuring penetration power at each wavelength. Tissue has a high OD at the shorter visible wavelengths of $415 \mathrm{~nm}$ blue and $590 \mathrm{~nm}$ yellow. However, with a shift of only $49 \mathrm{~nm}$, the $633 \mathrm{~nm}$ wavelength penetrates 10,000 times better than yellow, and the deepest penetration rate is at $830 \mathrm{~nm}$ in the invisible near infrared. These wavelengths are important, because as LED systems developed in the first decade of the New Millennium, these wavelengths became the wavelengths of choice for the most scientifically serious LED-LLLT devices applicable over many specialties for multiple indications. The HEALITE II system (Lutronic Corporation, Goyang, South Korea) started out the second decade in 2011 as representing the optimum device to embody the true science of mutispecialty LED-LLLT, and continues that task to the present as will be described hereafter.

\section{LED-LLLT: WAVELENGTHS AND INDICATIONS}

What exactly is LED-LLLT? It is an exchange of energy between incident photons and their target, in which the photons give up their energy to the cells absorbing them, without heat and without damage. This increased energy boosts the action threshold of the cell, which is now photoactivated, the keystone of photobiomodulation. Photoactivated cells can accomplish a number of tasks. If the cells are damaged or compromised, they will be swiftly repaired, either by themselves, or with help from surrounding cells. If the cells have a function to perform, like fibroblasts synthesizing collagen, they will perform that function faster and more efficiently; and if there are not enough of that type of cell, then either proliferation will occur, or more cells will be recruited into the area via photochemotaxis. One, two or all three of these events can occur with photoactivated cells, and this enables achieving a viable clinical effect but athermally and atraumatically.

As cells are stimulated by rising levels of light energy, then the level of photobiomodulation also increases, but only up to a threshold which we'll call the damage threshold. If the stimulating light energy continues to rise, then a light-to-heat transfer begins to occur and cells begins to heat up, causing damage and changes which are reversible. At this stage the cells are still alive, however, but pumping even more light energy into the cells will exceed the next threshold, the survival threshold, and kill the cells: first by cooking them, coagulation, or blasting them apart, ablation through vaporization. In low level light therapy, LLLT, only photobiomodulation of the cells occurs, remaining below that damage threshold. If the light source is LEDs, then this is LED-LLLT.

As mentioned above, wavelength is of critical importance in LED-LLLT, since the wavelength determines the target, known as the chromophore. This might be a cell, a cellular organelle within the cell, or a substance. Wavelength also determines how deeply the light can intrinsically penetrate into the skin to reach the desired target, although there must be enough intensity for the correct wavelength to reach deeper targets with sufficient photon energy to photoactivate the cells. The HEALITE II system offers three main wavelengths: from the shortest wavelength they are $415 \mathrm{~nm}$ visible blue, $633 \mathrm{~nm}$ visible red, and $830 \mathrm{~nm}$ in the near-infrared (NIR). The $830 \mathrm{~nm}$ main wavelength is complemented by low intensity $590 \mathrm{~nm}$ visible yellow. Looking back to Fig. 1 above, the reader can see that these wavelengths are shown specifically on the photospectrogram showing light penetration into living human tissue. This degree of penetration matches each wavelength to specific targets, and Fig. 2 shows schematically the penetration of these 4 wavelengths into skin. In the following part, the three main wavelengths will be discussed regarding their optical properties in tissue, and the main clinical indications.

\section{$415 \mathrm{~nm}$}

The visible blue $415 \mathrm{~nm}$ has relatively poor penetration

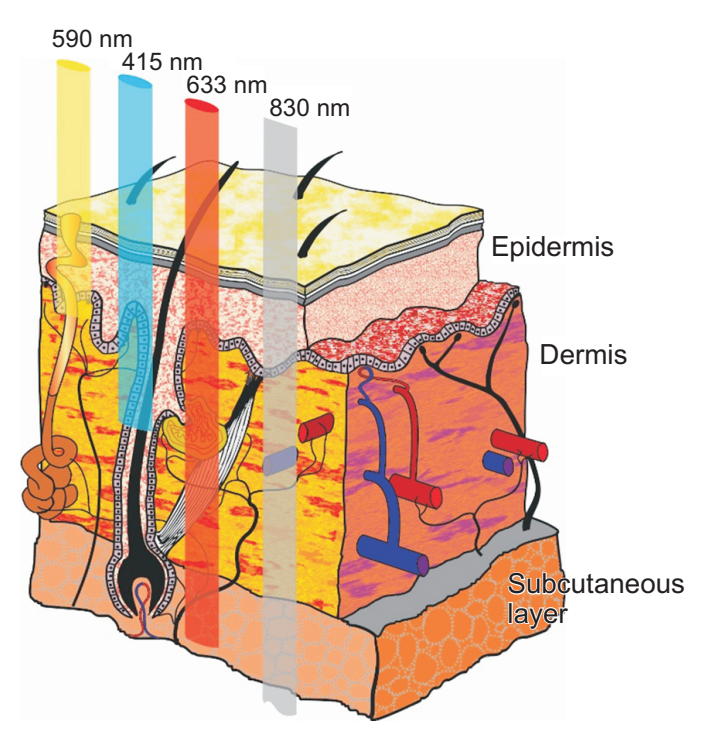

Fig. 2. A schematic illustrating the penetration of the HEALITE wavelengths into skin. 
into tissue because of high absorption in blood and melanin, but these are not biological targets for this wavelength. The penetration depth is around $1.5 \mathrm{~mm}$, so that the light can reach the sebaceous glands, and that is ideal because the only target for $415 \mathrm{~nm}$ is porphyrin. The main causative bacterium of acne vulgaris is Propionibacterium acnes ( $P$. acnes), and when acne become active, $P$. acnes contains endogenous porphyrins [10]. The $415 \mathrm{~nm}$ light activates the porphyrins through endogenous photodynamic therapy (PDT) to creat fatal oxidative stress within the $P$. acnes, which go into apoptosis, programmed cell death [11]. This dramatically cuts the number of $P$. acnes in the sebaceous glands, and thereby helps control inflammation. However, $415 \mathrm{~nm}$ treatment on its own can cause skin darkening, especially in Asian skin types, because the blue light is seen by melanocytes as dangerous for the skin so they produce more melanin. Adding $830 \mathrm{~nm}$ (or $633 \mathrm{~nm}$ ) to the $415 \mathrm{~nm}$ treatment stops the skin darkening and also helps with inflammation and wound healing [12].

\section{$633 \mathrm{~nm}$}

As can be seen from Fig. 2, this wavelength penetrates much more deeply into tissue, and before the $830 \mathrm{~nm}$ wavelength became the main HEALITE wavelength, visible red $633 \mathrm{~nm}$ energy was used for a large variety of indications including skin rejuvenation and wound healing. Now however its main indication is as the photoactivator for topically-applied aminolevulinic acid (5-ALA) in exogenous PDT for non-melanoma skin cancers (basal cell carcinoma, Bowen's disease) or actinic keratosis [13]. It can also be used in the single treatment approach for active acne and skin rejuvenation $[14,15]$. When 5-ALA is in contact with the skin, it creates porphyrins in the target tissue. However, the depth is much greater than the sebaceous glands, so activation with $415 \mathrm{~nm}$ would be firstly not deep enough, and secondly far too painful. There is another activation peak for porphyrins around $633 \mathrm{~nm}$, so the activation is both deep, and more gentle. $633 \mathrm{~nm}$ has also had some success in treatment of androgenic alopecia, and can be used to enhance the action of minoxidil [16].

\section{$830 \mathrm{~nm}$}

The wavelength of $830 \mathrm{~nm}$ has a very long history in LLLT, having first been extensively reviewed in 1988, which concerned systems based on laser diodes [6]. LEDs were not appropriate for clinical indications till the advent of the NASA LED in 1998, but no commercially-available $830 \mathrm{~nm}$ LED-LLLT system based on good science was available until
2005, and the first paper to show the clinical efficacy was by Lee et al. [17] in 2007. This is a pivotal paper, which compared $830 \mathrm{~nm}$ LED-LLLT on its own with $633 \mathrm{~nm}$ on its own and the sequential combination of these two wavelengths against a sham-irradiated control for skin rejuvenation. However, the paper also looked at the histology, histopathology and immunohistochemistry of the wound healing process which underpinned the excellent skin rejuvenation results. A further detailed study concentrated on the effect of $830 \mathrm{~nm}$ on the photodegranulation of mast cells as a critical component of accelerating the wound healing process [18]. The HEALITE II system (Lutronic, Goyang, South Korea) became commercially available in early 2011, and very quickly since then has featured in several peer-reviewed publications on wound healing [19], hypertrophic scar prevention [20], control of bacterial and viral infection $[19,21]$, dermatitis [22], burn wounds [23] and beneficial action on stem cell proliferation in vitro and in vivo [24]. $830 \mathrm{~nm}$ LEDLLLT has also shown very powerful synergy as adjunctive therapy after any kind of major or minor aesthetic/cosmetic procedure, shortening downtime by controlling erythema, discomfort and edema, and improving the clinical result [25]. Additional beneficial effects have been reported in turning back the skin ageing clock for the ageing face using $830 \mathrm{~nm}$ LED-LLLT either as a stand-alone approach, or in conjunction with other invasive or noninvasive methods [26].

\section{CONCLUSIONS}

HEALITE II embodies two unique technologies which set it apart from any other LED-LLLT system. LEDs are noncoherent, and emit a very divergent beam. Higher quality LEDs offer a slightly less divergent beam, however divergence lowers the photon intensity of the light energy. LEDs cannot be focused or collimated because the photons are noncoherent and totally out of phase, although they do have some directionality as they are emitted from the chip. Because of this, the light beam can be squeezed into a much less-divergent beam using a semicollimating lens. This technique gathers all of the light and minimizes light loss by side-scatter, projecting a higher photon intensity to the target with the same actual irradiance at the LED. In HEALITE, each panel of LEDs is fronted with an array comprising an optically clear plate embossed with semicollimating lenses precisely placed in front of each LED. This is called optical lens array technology (OLAT), and the dramatic increase in light intensity at the target is illustrated in Fig. 3, and is applied to all heads of the HEALITE system.

The second unique technology is found only in the $830 \mathrm{~nm}$ head, and is called photosequencing technology: 


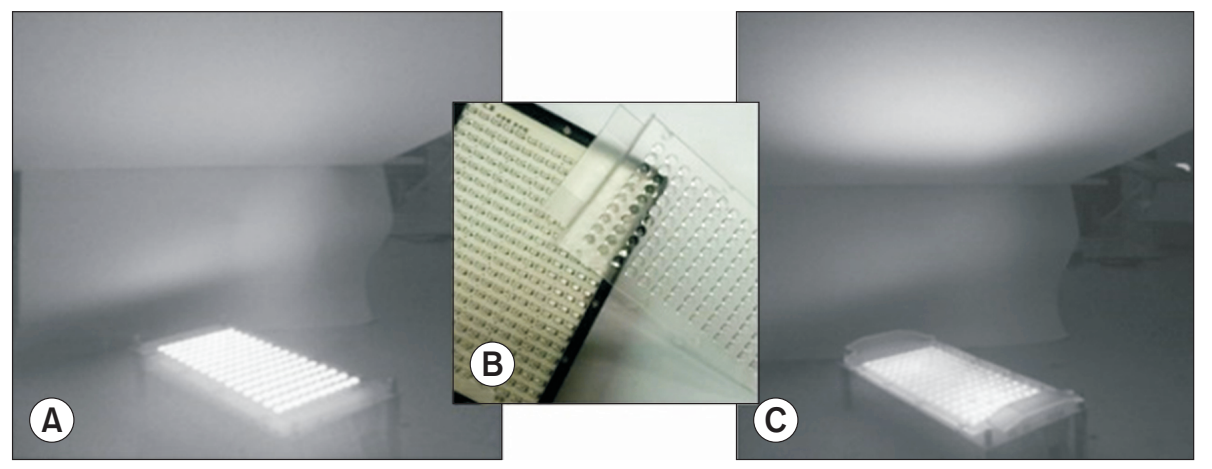

Fig. 3. The efficacy of optical lens array technology illustrated. (A) An $830 \mathrm{~nm}$ LED array without OLAT photographed with an infrared camera. Light is reaching the target, but a lot of light is lost to scatter. (B) The optical lens array seen as a clear plastic sheet embossed with semicollimating lenses. (C) The same array at the same output power with OLAT at work. All of the light has been concentrated on a specific area of the target, with much higher photon intensity.

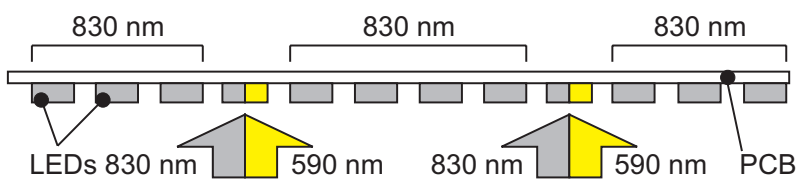

Fig. 4. The basics behind the $830 \mathrm{~nm}$ and $590 \mathrm{~nm}$ photosequencing technology: the schematic shows a HEALITE panel side on, with the 12 rows of LEDs illustrated. Note that the fourth LED in from each edge is a double-chip $830 \mathrm{~nm} / 590 \mathrm{~nm}$ LED. Please see the text for details.

it works like this. In Fig. 4, you can see a schematic of a HEALITE panel viewed end-on. There are 12 rows of LEDs, 30 LEDs in each row. The $4^{\text {th }}$ LED in from each end is a double-chip LED emitting both $830 \mathrm{~nm}$ and $590 \mathrm{~nm}$. When treatment is started with the $830 \mathrm{~nm}$ head, for the first 1 minute only the $590 \mathrm{~nm}$ LEDs are illuminated, one panel at a time, for $1 \mathrm{~s}$ each. There are 5 panels and 12 cycles of scanning, so that accounts for the first minute of treatment. The target for the $590 \mathrm{~nm}$ is mostly only the epidermis (see Fig. 2 above), especially the mother keratinocytes and Merkel cells. As they have many mitochondria, and $590 \mathrm{~nm}$ has mitochondria as its target, extracellular levels of adenosine triphosphate (ATP) and calcium ion $\left(\mathrm{Ca}^{++}\right)$signaling increase in the epidermis, very beneficial for the epidermal environment. After that, all 1,800 deep-targeting $830 \mathrm{~nm}$ LEDs are activated but the $590 \mathrm{~nm}$ LEDs keep scanning. Now there is no clinical effect from $590 \mathrm{~nm}$ as the much stronger $830 \mathrm{~nm}$ energy washes out the ultra-weak $590 \mathrm{~nm}$ light. However, $830 \mathrm{~nm}$ is in the near-infrared and invisible, so that the patient will still see the $590 \mathrm{~nm}$ light cycling away, and thus will know that something is in fact happening with their treatment. The combination of these two wavelengths thus benefits both the dermis and the epidermis.

With its three wavelengths and unique optical lens array and photosequencing technologies, the HEALITE II LEDLLLT system covers an ever-widening range of indications for light-emitting diode phototherapy with safety, efficacy and reliability. The treatment heads, mounted on a placeand-stay articulated arm, are easily interchangeable, and the system is fully mobile on a stable, lockable castered base. HEALITE offers multispecialty use either as a standalone system or, perhaps more interestingly, as a powerful adjuvant tool to minimize patient downtime and maximize treatment efficacy after any invasive, minimally invasive or even noninvasive treatment approach. Backed by a large body of published evidence, HEALITE has an indispensable place in in the aesthetic/cosmetic setting, in the plastic surgery clinic, in the general practitioner's office, sports medicine clinic and physiotherapy center. HEALITE really is the true science of multispecialty light-emitting diode low level light therapy.

\section{CONFLICT OF INTEREST}

No potential conflict of interest relevant to this article was reported.

\section{REFERENCES}

1. Giese AC. The sun, sun myths, and sun worship. In: Giese AC, editor. Living with Our Sun's Ultraviolet Rays. Boston: Springer; 1976. p.1-16.

2. Gøtzsche PC. Niels Finsen's treatment for lupus vulgaris. J R Soc Med 2011;104:41-2.

3. Bradley A. Light therapy for neonatal jaundice [online]. [cited 2020 Jun 22]; Available from: https://embryo.asu.edu/ pages/light-therapy-neonatal-jaundice

4. Maiman TH. Stimulated optical radiation in ruby. Nature 1960;187:493-4.

5. Mester E, Spiry T, Szende B, Tota JG. Effect of laser rays on wound healing. Am J Surg 1971;122:532-5.

6. Ohshiro T, Calderhead RG. Low Level Laser Therapy a Practical Introduction. New York: John Wiley \& Sons; 1988.

7. Whelan HT, Houle JM, Whelan NT, Donohoe DL, Cwiklinski $\mathrm{J}$, Schmidt $\mathrm{MH}$, et al. The NASA light-emitting diode medical program-progress in space flight and terrestrial applications. AIP Conf Proc 2000;504:37-43.

8. Smith KC. Laser (and LED) therapy is phototherapy. Pho- 
tomed Laser Surg 2005;23:78-80.

9. Whelan HT, Smits RL Jr, Buchman EV, Whelan NT, Turner SG, Margolis DA, et al. Effect of NASA light-emitting diode irradiation on wound healing. J Clin Laser Med Surg 2001;19:30514.

10. Nitzan $Y$, Kauffman M. Endogenous porphyrin production in bacteria by $\delta$-aminolaevulinic acid and subsequent bacterial photoeradication. Lasers Med Sci 1999;14:269-77.

11. Webber J, Luo Y, Crilly R, Fromm D, Kessel D. An apoptotic response to photodynamic therapy with endogenous protoporphyrin in vivo. J Photochem Photobiol B 1996;35:209-11.

12. Lee SY, You CE, Park MY. Blue and red light combination LED phototherapy for acne vulgaris in patients with skin phototype IV. Lasers Surg Med 2007;39:180-8.

13. Morton CA, Whitehurst C, Moseley H, Moore JV, Mackie RM. Development of an alternative light source to lasers for photodynamic therapy: 3. Clinical evaluation in the treatment of pre-malignant non-melanoma skin cancer. Lasers Med Sci 1995;10:165-71.

14. Pollock B, Turner D, Stringer MR, Bojar RA, Goulden V, Stables GI, et al. Topical aminolaevulinic acid-photodynamic therapy for the treatment of acne vulgaris: a study of clinical efficacy and mechanism of action. Br J Dermatol 2004;151:616-22.

15. Lowe NJ, Lowe P. Pilot study to determine the efficacy of ALA-PDT photo-rejuvenation for the treatment of facial ageing. J Cosmet Laser Ther 2005;7:159-62.

16. Hamblin MR. Photobiomodulation for the management of alopecia: mechanisms of action, patient selection and perspectives. Clin Cosmet Investig Dermatol 2019;12:669-78.

17. Lee SY, Park KH, Choi JW, Kwon JK, Lee DR, Shin MS, et al. A prospective, randomized, placebo-controlled, doubleblinded, and split-face clinical study on LED phototherapy for skin rejuvenation: clinical, profilometric, histologic, ultra- structural, and biochemical evaluations and comparison of three different treatment settings. J Photochem Photobiol B 2007;88:51-67.

18. Calderhead RG, Kubota J, Trelles MA, Ohshiro T. One mechanism behind LED phototherapy for wound healing and skin rejuvenation: key role of the mast cell. Laser Ther 2008;17:141-8.

19. Min PK, Goo BL. 830 nm light-emitting diode low level light therapy (LED-LLLT) enhances wound healing: a preliminary study. Laser Ther 2013;22:43-9.

20. Park YJ, Kim SJ, Song HS, Kim SK, Lee J, Soh EY, et al. Prevention of thyroidectomy scars in Asian adults with low-level light therapy. Dermatol Surg 2016;42:526-34.

21. Park KY, Han TY, Kim IS, Yeo IK, Kim BJ, Kim MN. The effects of $830 \mathrm{~nm}$ light-emitting diode therapy on acute herpes zoster ophthalmicus: a pilot study. Ann Dermatol 2013;25:163-7.

22. Kim WS, Calderhead RG. Is light-emitting diode phototherapy (LED-LLLT) really effective? Laser Ther 2011;20:205-15.

23. Lee GY, Kim WS. The systemic effect of 830-nm LED phototherapy on the wound healing of burn injuries: a controlled study in mouse and rat models. J Cosmet Laser Ther 2012;14:107-10.

24. Min KH, Byun JH, Heo CY, Kim EH, Choi HY, Pak CS. Effect of low-level laser therapy on human adipose-derived stem cells: in vitro and in vivo studies. Aesthetic Plast Surg 2015;39:77882.

25. Calderhead RG, Kim WS, Ohshiro T, Trelles MA, Vasily DB. Adjunctive $830 \mathrm{~nm}$ light-emitting diode therapy can improve the results following aesthetic procedures. Laser Ther 2015;24:277-89.

26. Calderhead RG, Vasily DB. Low level light therapy with light-emitting diodes for the aging face. Clin Plast Surg 2016;43:541-50. 